\title{
Review \\ The intraductal approach to the breast: raison d'être
}

\author{
Bonnie L King ${ }^{1}$ and Susan M Love ${ }^{2}$
}

\author{
1Department of Biological Sciences, Quinnipiac University, Mt Carmel Ave, Hamden, CT 06518-1908, USA \\ 2Dr Susan Love Breast Cancer Research Foundation, Via de la Paz, Pacific Palisades, CA 90272, USA
}

Corresponding author: Susan M Love, slove@earthlink.net

Published: 21 April 2006

This article is online at http://breast-cancer-research.com/content/8/2/206

(c) 2006 BioMed Central Ltd

Breast Cancer Research 2006, 8:206 (doi:10.1186/bcr1410)

\begin{abstract}
Opportunities for the detection, prediction, and treatment of breast cancer exist at three biological levels: systemically via the blood, at the whole organ level, and within the individual ductal lobular structures of the breast. This review covers the evaluation of approaches targeted to the ductal lobular units, where breast cancer begins. Studies to date suggest the presence of 5 to 12 independent ductal lobular systems per breast, each harboring complex cellular fluids contributed by local and systemic processes. New techniques for accessing and interrogating these systems offer the potential to gauge the microenvironment of the breast and distill biological risk profiles.
\end{abstract}

\section{Introduction}

All breast cancer originates in the lining of the ductal lobular units [1]. Most pathologists who have studied breast cancer through the whole organ technique have demonstrated that the majority of lesions are multifocal within the confines of one ductal system [2-5]. The most elegant example was Roland Holland's [6] classic paper describing 82 meticulous dissections of mastectomy specimens in which all but one showed contiguous disease. This has led to the general belief that most breast cancers arise in one ductal system. Although this suggests that the ductal lobular system is the most important anatomical unit in breast cancer development, there has been little interest until recently in its exploration. The recent development of techniques to access the ductal systems, including catheters for cannulation and endoscopes, as well as new analytical approaches to the ductal fluid, have led to a renaissance of interest in this area [7].

\section{Anatomy of the ductal systems}

Although most surgical textbooks state without attribution that there are 15 to 20 ductal openings on the nipple, no scientific source for this pronouncement has been identified. This lack of hard data is confounded by an absence of conformity in terms and definitions. Before the potential for the intraductal approach can be evaluated we must define what is meant by a ductal system, and describe the limited data that exist. To most pathologists, imagers, and clinicians, a breast ductal system or lobe is a unit consisting of an opening on the surface of the nipple leading to a lactiferous duct, which branches into segmental and terminal ducts that end as lobules. The first question then, is how many of these lobes or ductal systems are there in the average breast?

The best study dates back to 1841 when Astley Cooper [8] injected wax through the nipple at autopsy in an attempt to outline the anatomy of the milk ducts (Figure 1a). He described being able to inject at most 12 lactiferous ducts, and more commonly 7 to 10 per nipple. Love and Barsky [9] observed over 200 lactating women in order to map milk duct orifices and identified an average of 5 to 9 openings. Teboul and Halliwell [10] reported on over 6,000 ultrasound studies of the breast ducts and described 5 to 8 'milk pores' in the nipple. Finally, Ramsay and colleagues [11] studied 21 lactating women with ultrasound and described 6 to 12 main ducts.

What then is the source of the 15 to 20 figure commonly quoted? Cooper, Sartorius and colleagues [12] and Dietz and colleagues [13] have all described additional nonarborizing structures accessed through the nipple, varying from 1 to $4 \mathrm{~cm}$ in length and independent from the lobes. Although each author has given these structures a different name (tubercles, sebaceous glands, rudimentary ducts, or atrophic ducts), their descriptions are identical (Figure 1c,d). These structures appear identical to lactiferous ducts when seen behind the nipple in cross section, but do not function as such due to their lack of lobules. In addition to the two types of structures accessible from the nipple (true ducts and rudimentary ducts) Going and Moffat [14] identified other tubular structures in their extensive three-dimensional reconstruction of a nipple. They described numerous structures tapered down to a minute lumen at their origin

DCIS = ductal carcinoma in situ; FISH = fluorescence in situ hybridization; LCIS = lobular carcinoma in situ; NAF = nipple aspirate fluid; SELDITOF MS = surface-enhanced laser desorption and ionization-time of flight mass spectrometry. 


\section{Figure 1}
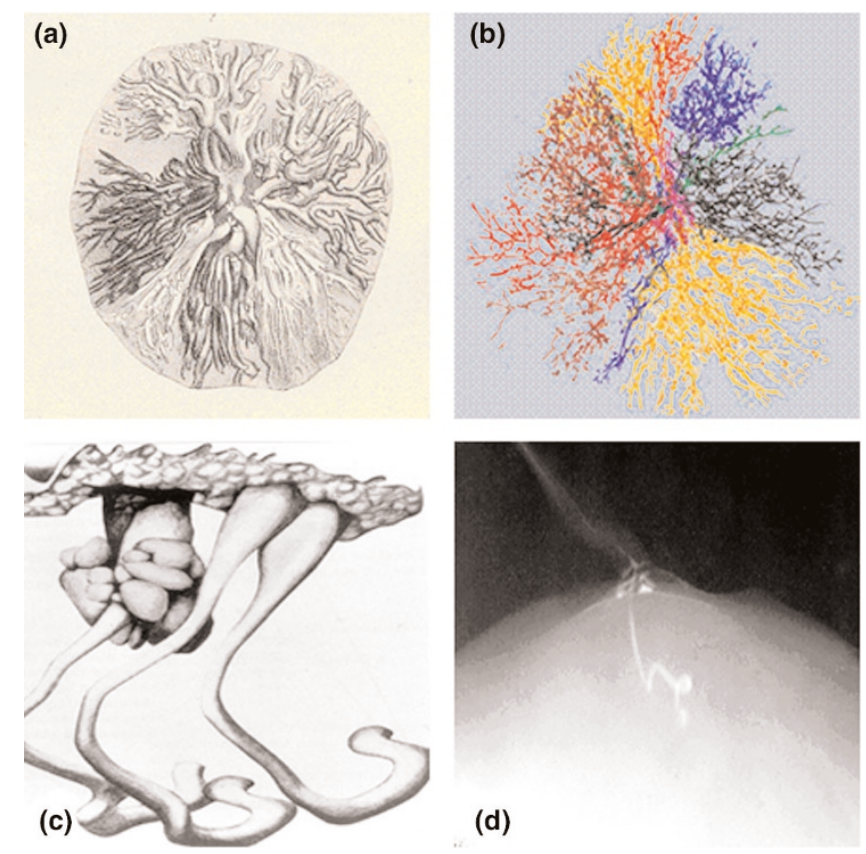

Ductal systems of the breast. (a) Ductal systems as depicted by Astley Cooper (1841). (b) Computer reconstruction of ductal systems as depicted by James Going and colleagues (2004; copyright the Pathological Society of Great Britain and Ireland; reproduced with permission granted by John Wiley and Sons Ltd on behalf of the PathSoc). (c) 'Tubercles' as depicted by Astley Cooper (1841).

(d) 'Tubercle' as depicted by Otto Sartorius (1972).

from the deep aspect of the nipple. Although they appeared as ducts in cross section, they did not exit the nipple. Since they did not trace these structures into the breast, it is not clear what they represent, or if they extend distally into the breast parenchyma. Ohtake and colleagues [2] used a subcutaneous mastectomy as the basis of their computerized three-dimensional reconstruction and described 16 ductal systems correlating with the 16 collecting ducts at the nipple. Although it is difficult to determine from their computerized models whether some of the structures might be rudimentary, they vary in size and extent. This variability was confirmed recently by Going and Moffat [14], whose computerized reconstruction of a breast showed a variation in size of the lobes, with the largest six ductal systems constituting $75 \%$ of the breast volume (Figure 1b).

Another issue, brought up by Ohtake and colleagues' study [2], is whether ductal systems anastomose with each other. Cooper stated definitively that he did not find evidence of this in his dissections. Love and colleagues [9] and Going and Moffat also showed no evidence of anastomoses. It is certainly possible that the definition of a single ductal system may differ in these studies, with all connecting branches considered part of one system in some reports and part of two anastomosing systems in others.
Thus, one explanation for the discrepant observation of 5 to 9 versus 15 to 20 ducts may be the additional tubular structures that mimic the appearance of ducts behind the nipple, but do not contribute significantly to the ductal lobular infrastructure of the breast. The nature of these additional structures and their role in breast physiology and pathology has yet to be described. Collectively, these data suggest that there are 5 to 12 significant, independent, arborizing lactiferous ductal systems, each of which cover a finite portion of the breast geography, and can be assessed from the nipple.

\section{Physiology}

The limitation in knowledge regarding the anatomy of the milk ducts extends equally to their physiology. Sampling of nipple aspirate fluid (NAF) from the nipple through massage and a suction device was first reported by Papanicolou and colleagues in 1953 [15]. Since then many researchers have analyzed this fluid and found that it has a complex composition with distinctive biochemical and cellular features. Petrakis [16] did the most extensive analysis of NAF and identified a variety of cells, proteins, fatty acids and hormones (Table 1). An important question concerns the degree to which these constituents are contributed to breast fluids via passive versus active processes in the non-lactating breast.

Reproductive hormones have been the best studied in this regard because of their association with breast cancer [17]. Many researchers have noted that the concentrations of estrogens in breast fluids are significantly higher than in serum, with little variation with the menstrual cycle or menopause $[18,19]$. Since breast epithelial and stromal cells have the ability to synthesize estrogen through aromatase or sulfatase, and the ductal fluid contains estrogen precursors, it has been hypothesized that local synthesis is one means of generating elevated estrogen levels in ductal fluid [20]. Chatterton and colleagues [21] demonstrated that estrogen precursors were more abundant in breast fluids than estrogen itself, giving some support to this hypothesis. They also showed, however, that altered hormone levels in association with oral contraceptive pills or hormone replacement therapy are reflected in the fluid after several days, suggesting that there is some diffusion and concentration going on as well. Interestingly both hormones and cholesterol levels decline following pregnancy. These lower levels persist for several years and then gradually rise to prepregnancy levels, suggesting a more complex process [22].

It has also been suggested that each ductal compartment is a stagnant pond with little fluid exchange. As with milk, both nicotine and continine have been found in the ductal fluid of smokers [16]. There is at least some evidence for two way exchange, however, since intraductal water soluble contrast material is completely absorbed within 15 to 20 minutes [12].

\section{Fluid sampling techniques}

NAF is usually obtained through massage and a simple suction device. Although this is successful in $80 \%$ of non- 
Table 1

\begin{tabular}{|c|c|c|c|c|c|}
\hline Proteins & Immunoglobulins & Fats & Hormones & Electrolytes & Cells \\
\hline Alpha 1 lipoprotein & $\lg A$ & Lauric & Prolactin & Sodium & Epithelial \\
\hline Alpha 1 acid glycoprotein & $\lg M$ & Myristic & Estrone & Potassium & Myoepithelial \\
\hline Alpha 2 macroglobulin & IgG $\mathrm{H}$ chain & Myristoleic & Estradiol & Chloride & Macrophages \\
\hline Alpha 2 HS glycoprotein & $\lg G \mathrm{~L}$ chain & Palmitic & DHEAS & Calcium & Neutrophils \\
\hline Alpha 1 antitrypsin & $\lg E$ & Palmitoleic & Progesterone & Phosphate & Lymphocytes \\
\hline Trypsin & $\lg \mathrm{D}$ & Cholesterol & Growth hormone & & Mast Cells \\
\hline Beta liprotein & & Cholesterol epoxides & Testosterone & & Erythrocytes \\
\hline Beta glycoprotein III & & & TGF- $\alpha$ & & \\
\hline Ceruloplasmin & & & EGF & & \\
\hline \multicolumn{6}{|l|}{ Prealbumin } \\
\hline \multicolumn{6}{|l|}{ Human lysozyme } \\
\hline$\alpha$-Lactalbumin & & & & & \\
\hline
\end{tabular}

DHEAS, dihydroepiandrosterone sulfate; EFG, epidermal growth factor; TGF- $\alpha$, transforming growth factor-alpha.

lactating women, it is usually elicited from only one or two ducts. In an attempt to better access the whole breast, technologies for duct cannulation, including catheters and ductoscopes, have been developed. The first reported lavage, referred to as a 'rinse', was performed by LeBorgne [23] in Uruguay in 1953. He dilated the ducts, instilled saline, and then massaged fluid out manually. Sartorius and colleagues [12] combined lavage with contrast ductography to collect the fluid as NAF after imaging. Love developed an intraductal catheter, which used a double lumen to maintain the patency of the duct while lavaging it [33]. These firstgeneration devices have allowed proof of principle.

Most breast cancers are thought to arise from the junctions of the terminal ductal lobular units of the mammary tree, and evidence suggests that lavage procedures are capable of delivering fluid to, and harvesting cells from, these regions of the gland. Several studies involving the intraductal delivery of dyes to demarcate the path of lavage fluids have demonstrated permeation of the lobular-alveolar portion of the ductal systems [24-26]. Moreover, the procedure has collected lavage cells exhibiting cytological features of lobular carcinoma in situ (LCIS) from a patient with pathology-confirmed LCIS [24]. In addition, lavage study participants have reported feeling the cooler (room) temperature of the lavage saline circulating within chest wall and axial regions (unpublished observations). Collectively, these data suggest that epithelial cells can be collected from the terminal reaches of the mammary tree, and that these samples can be used to detect malignant cells in a subset of women with breast cancer, albeit with low sensitivity.

The technology is not without its limitations, however. One technical challenge is that it is not always possible to tell whether a duct has been perforated in the process of cannulation. Thus, some lavages may actually represent a sampling of stroma rather than ductal fluid. In addition, it is currently not possible to correlate the findings in ductal fluid with the anatomy of the structure being lavaged (true ductal system, rudimentary, or atrophied duct). Lavaging under direct vision with a ductoscope $[27,28]$ can help with these distinctions but is time consuming, and appropriate scopes are not readily available. New devices currently in development will be able to identify all the nipple orifices, differentiate between them, and facilitate efficient cannulation, allowing the field to progress more rapidly.

\section{Origins of ductal fluid}

Although many assumptions have been made about the pathophysiology of NAF, it is still not clear whether it represents a systemic or local process, or both. The epidemiology of NAF production would suggest a systemic process [29]. It is more commonly elicited from women aged 35 to 50 years, of non-Asian ethnic origin, who experienced early age of menarche, and who have lactated. Moreover, reductions in NAF yield are associated with selective estrogen receptor modulators and oophorectomy [30,31]. This would suggest that systemic hormonal stimulation of the breast leads to NAF production, but does not explain why only a few ducts produce it.

Some insight can be gained by looking at the categories of spontaneous nipple discharge, which can originate due to local and systemic influences (Table 2). It is certainly possible that as with pathological discharge, some NAF is systemic in origin while other types represent local pathology. Sanchez and colleagues [32] used polyacrylamide gel electrophoresis to analyze NAF protein banding patterns and delineated two 
Table 2

\begin{tabular}{|c|c|c|c|}
\hline & \multicolumn{3}{|c|}{ Types of spontaneous discharge } \\
\hline & Galactorrhea & Pathological & Physiological \\
\hline Characteristics & Milky & Sero-sanguinous or watery & Colored, opalescent \\
\hline Extent & Bilateral & One duct & Multiple ducts \\
\hline Color & Uniform & & $\begin{array}{l}\text { Variable in different ducts: green, } \\
\text { brown, yellow, etc. }\end{array}$ \\
\hline Etiology & $\begin{array}{l}\text { Physiological/pathological galactorrhea } \\
\text { (increased prolactin) }\end{array}$ & $\begin{array}{l}\text { Intraductal proliferation (papilloma, } \\
\text { DCIS, carcinoma) duct ectasia }\end{array}$ & $\begin{array}{l}\text { Physiological, duct ectasia, } \\
\text { microcysts }\end{array}$ \\
\hline Origin of process & Systemic & Local & Multiple ducts in one or both breasts \\
\hline
\end{tabular}

types. One was more similar to milk, and was found in women who had given birth in the last four years or were on oral contraceptives. This type was also more common in women with breast cancer. The other type closely resembled cyst fluid with regard to color and components, and was more common in women with benign disease. Other studies have demonstrated intraductal papillary processes as the source of atypical cells in NAF, suggesting that local as well as systemic factors influence NAF production, both of which need to be taken into account in our thinking.

Initially, the presumption was made that the duct that secreted most actively and, therefore, was most readily accessible, would be the 'sentinel' duct, representing the status of the breast [33]. In fact, if NAF represents a field defect within the whole breast, one would expect that sampling any duct with NAF in a breast with cancer would demonstrate atypical cells. Recent studies by Khan and colleagues [25] and Brogi and colleagues [24] have demonstrated that this is not the case. Another assumption was that the fluid yielding ducts would be the ones most likely to harbor atypical and malignant cells. On the contrary, several investigations [34-36] have demonstrated atypical cells in non-discharging ducts at a rate similar to their incidence in discharging ducts, and Khan and colleagues [37] showed that most ducts with ductal carcinoma in situ (DCIS) did not produce NAF. These findings are not surprising since spontaneous serosanguinous or watery discharge represents in situ or invasive cancer only about $5 \%$ of the time. Much of the data generated from the analysis of NAF fluid and cancer risk may be a result of pooling fluid from several different pathological mechanisms, potentially in the same breast. Current biomarker and proteomic analysis may give further insight into this situation.

In fact, the microenvironment of each duct may be distinct with regard to many properties. Khan and colleagues [35] have shown different estrogen and estrogen precursor levels in different ducts. Figure 2 shows NAF from several ducts in one nipple and the different colors of secretion suggest that indeed the fluid from separate ducts has distinct properties. Our unpublished observations have suggested independence and variability between ducts, but as with Khan and colleagues' data, these findings were obtained with lavage. When doing lavage there is always a risk of unidentified perforation, which would cloud the data. A critical goal is to define interductal variation at the genetic, biochemical and cellular levels within the normal and diseased breast. We are currently doing a lavage study using ductoscopy to confirm the anatomy and comparing hormone, protein, cell and biomarker levels in at least three ducts per woman in an attempt to answer this question. It does appear that cytology is not the same in all the ducts, and it is certainly possible that some ductal contents are local, whereas others relate to the whole breast.

\section{Identification of breast abnormalities}

The evaluation of intraductal approaches for detecting abnormalities has been based on the prevailing model of breast cancer progression, in which epithelial cells lining the ductal lobular systems progress through successive stages of hyperplasia, atypical hyperplasia, carcinoma in situ (DCIS/LCIS), and invasive breast cancer. The mammary gland is a renewal tissue that exfoliates an unknown proportion of its epithelial cells into the glandular lumina. An initial assumption underlying intraductal approaches has been that cells representing each stage of breast cancer progression are shed into the ductal systems, and are accessible for collection. In keeping with the cervical PAP smear paradigm, cytology evolved as the 'gold standard' for the evaluation of breast fluid abnormalities, which have generally been classified according to a five-point scale consisting of ICMD (insufficient cells to make a diagnosis), benign, mildly or markedly atypical, and malignant categories. Over the years several paired NAF and lavage studies have been performed to evaluate the correlation of these cytological classifications with their histopathological counterparts. 
Figure 2

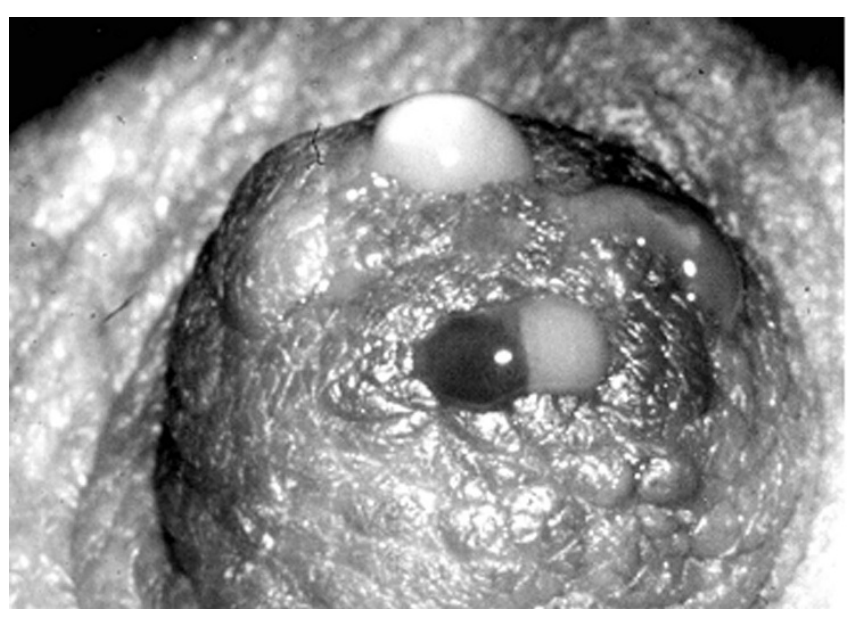

Drops of nipple aspirate fluid from four duct openings display varied coloration, suggesting that the ductal systems of the breast are anatomically distinct, and that some breast fluid properties exhibit interductal variation.

In a pioneering study, King and colleagues [38] detected atypical NAF cytology in 54\% and $70 \%$ of benign and breast cancer cases, respectively, diagnosed with histological atypical proliferative disease, demonstrating a strong association between the presence of cytological and histological atypia. However, correlations for the later stages of breast cancer progression have been weaker. In the same series, King and colleagues $[12,24,25,39,40]$ identified malignant NAF cytology in only $21 \%$ of breast cancer cases, and subsequent paired NAF and lavage studies have revealed similar correlations for advanced lesions. This trend may be explained in part by biological factors that determine the availability and collection of malignant cells in breast fluids.

Early correlative NAF studies by Sartorius and colleagues [12] failed to diagnose invasive breast cancers larger than $0.8 \mathrm{~cm}$, leading them to suggest that larger lesions may disrupt the integrity of the ductal system, preventing the exfoliation of malignant cells into the glandular lumina. Although extravasation may explain some findings, a review of subsequent paired NAF and lavage studies reveals the detection of at least some malignant lesions ranging from 1.5 to $11.5 \mathrm{~cm}$ by breast fluid cytology [39-43]. The exfoliation of tumor cells into the ductal systems may be determined by additional variables, including abnormal ductal branching and stromal responses associated with breast cancer progression. In some studies, atypical breast fluid cytology has been detected with higher frequency in women with malignant breast disease, leading to the suggestion that it is a marker of underlying malignancy $[25,38]$.

In keeping with the hypothesis that pre-invasive lesions would be more likely to shed cells into the ductal systems, others have examined the sensitivity of intraductal approaches to identify DCIS. Krishnamurthy and colleagues [40] detected malignant NAF cytology in $27 \%$ of pure DCIS cases, versus only $4 \%$ of invasive breast cancer cases, and found that the likelihood of detecting malignant cells was related to the extent of DCIS within the breast. In contrast, Brogi and colleagues [24] did not identify malignant cytology in any of the ductal lavage specimens collected from a series of mastectomy patients that included 24 breasts containing DCIS, even when dye administration confirmed lavage was performed on DCIS-containing ducts.

Khan and colleagues [37], who performed pre-biopsy lavage on women with mammographically detected microcalcifications, reported no malignant cytology in association with nine cases of histopathologically confirmed DCIS. In this study, ductography was performed to determine the overlap of lavaged ducts with areas of calcifications associated with DCIS, and revealed only one instance of overlap (in which the lavage was classified as benign). Four of the nine DCIS lesions identified by surgical pathological evaluation in this study were associated with non-fluid-yielding ducts, which had not been lavaged. This finding underscores the critical issue of duct sampling procedures, which historically have been targeted to the subset of ducts that produce fluid during the NAF procedure, and thus have led to biased sampling.

The selective sampling of fluid-producing ducts may be one of the contributing factors underlying the observed low sensitivity of cytology to detect malignant cells in breast fluids. As we have noted, the pathophysiological significance of NAF production during the different stages of breast cancer progression is not understood, and several recent studies have indicated that not all ductal systems with atypical and malignant lesions discharge fluid during the NAF procedure [24,25,34,36,37]. Such ducts were thus not sampled during the majority of the paired studies to date.

Although there are a number of complex variables, the above studies suggest that cytological/histopathological correlations appear to be stronger for the early stages of breast cancer progression, particularly for atypical hyperplasia, regarded as one of the strongest biological risk factors for breast cancer development $[44,45]$. Seminal studies by Page and Dupont demonstrated that a diagnosis of histological atypia via surgical biopsy is associated with a five-fold increase in relative risk for future invasive breast cancer development $[44,45]$. Cytological atypia diagnosed in fluids obtained by nipple aspiration and random periareolar fine needle aspiration is associated with a similar two- to five-fold increase [46-48]. Because a diagnosis of atypia through a variety of modalities has consistently been associated with elevated risk for breast cancer development, it is being widely evaluated as a risk marker in studies that sample breast tissue. The ductal lavage technique has consistently revealed atypical hyperplasia in at least a third of the specimens 
Table 3

\begin{tabular}{|c|c|c|c|c|c|c|}
\hline \multirow[b]{2}{*}{ Fluid collection } & \multicolumn{2}{|c|}{ Cytology } & \multicolumn{3}{|c|}{ Biomarker } & \multirow[b]{2}{*}{ Ref. } \\
\hline & Sensitivity & Specificity & Assay & Sensitivity & Specificity & \\
\hline \multirow[t]{2}{*}{ Nipple discharge } & $33 \%$ palpable cases & NA & CEA immunoassay & $75 \%$ & $89 \%$ & [42] \\
\hline & $14 \%$ nonpalpable cases & NA & & $80 \%$ & $89 \%$ & \\
\hline $\begin{array}{l}\text { Nipple discharge/ } \\
\text { ductography, } \\
\text { milking/washing } \\
\text { ducts with saline }\end{array}$ & $30 \%$ & $100 \%$ & LOH-PCR & $70 \%$ & $83 \%$ & [73] \\
\hline ROBE & $\begin{array}{c}\mathrm{ICMD} / \text { no } \\
\text { malignant cytology }\end{array}$ & $\begin{array}{c}\mathrm{ICMD} / \text { no } \\
\text { malignant cytology }\end{array}$ & MSP & $\begin{array}{c}85 \% \\
29 \% \text { DCIS }\end{array}$ & $80 \%$ & [51] \\
\hline Lavage & $33 \%$ & $89 \%$ & $\mathrm{FISH}$ & $100 \%$ & $100 \%$ & [70] \\
\hline Lavage & $47 \%$ & $79 \%$ & $\mathrm{FISH}$ & $71 \%$ & $89 \%$ & [39] \\
\hline NAF & $59 \%$ & NA & MSP & $82 \%$ & $100 \%$ & [43] \\
\hline Lavage & $31 \%$ & $100 \%$ & SELDI-TOF MS & $75 \%$ & NA & [41] \\
\hline
\end{tabular}

Comparison of cytology and biomarkers in paired studies in which breast fluids were collected presurgically from women scheduled for excisional breast biopsies or mastectomies. Sensitivities reflect the detection of invasive and/or ductal carcinoma in situ (DCIS), except when noted. CEA, carcinoembryonic antigen; FISH, fluorescence in situ hybridization; ICMD, insufficient cells to make a diagnosis; LOH-PCR, PCR-based loss of heterozygosity; MSP, methylation-specific PCR; NA, not available; NAF, nipple aspirate fluid; ROBE, routine operative breast endoscopy; SELDI-TOF MS, surface-enhanced laser desorption and ionization-time of flight mass spectrometry.

collected from all populations of women, including breast cancer patients [24,25,39], asymptomatic high-risk women $[31,33,34]$, and healthy volunteers recruited from the general population (unpublished data). Due to these findings, the cytological evaluation of ductal lavage specimens has been heralded as a potential risk assessment tool.

However, there are a number of challenges associated with the cytological evaluation of ductal lavage samples. To date, long-term follow-up has not been completed for lavage studies, and the prognostic significance of atypia detected by this technique remains undefined. It has been argued that extrapolation from NAF studies may be inappropriate given that it is unknown what proportion of the cells collected by lavage represent naturally exfoliated cells versus intact cells that are dislodged as the result of the procedure. However, sampling via the random periareolar fine needle aspiration technique is independent of naturally occurring exfoliation and yet reveals a striking association between cytological atypia and short-term risk [48]. A more critical issue, associated with the diagnosis of atypia by any modality, is that despite the elevation of relative risk, the majority of women diagnosed with histological or cytological atypical hyperplasia do not develop breast cancer $[46,49]$. In addition, most of the women who developed breast cancer in NAF studies with long-term follow-up had not been diagnosed with atypia [46]. Additional challenges associated with exfoliative breast cytology stem from the fact that it is a subjective procedure often plagued by low reproducibility and poor inter-observer agreement, particularly with regard to the classification of atypical hyperplasia [3].
In summary, exfoliative cytology has helped generate proof of principle for detecting breast cancer-associated abnormalities in intraductal fluids, has established intriguing associations between atypical breast fluid cells and the presence or risk for developing breast cancer, and has revealed the heterogeneity of breast fluid cell populations. However, cytological evaluation has consistently demonstrated low sensitivity to detect malignancy in NAF and lavage studies (Table 3), revealed a high degree of prognostically ambiguous atypical cytology, and failed to identify the majority of women destined to develop breast cancer. Some of these limitations may be due to the fact that atypical hyperplasia is generally a multicentric process, and can be associated with multiple etiologies.

\section{Biomarkers}

To overcome the limitations and challenges of cytology, a variety of biomarker approaches have been developed to enable the identification of genetic, epigenetic, and proteomic alterations in rare cells or soluble molecules in breast fluids. Figure 3 shows the use of interphase fluorescence in situ hybridization (FISH) to detect aneusomy in an isolated cluster of epithelial cells from a lavage classified as cytologically benign [39]. While the efficient identification of such rare events by in situ assays requires the application of automated imaging systems, infrequent genetic and epigenetic alterations can be routinely amplified using PCRbased methods. Methylation-specific PCR (MSP) amplifies cancer-associated gene promotor methylation events, and the quantitative multiplex version of this assay (OM-MSP) has the capacity to detect 1 methylated copy among 100,000 


\section{Figure 3}

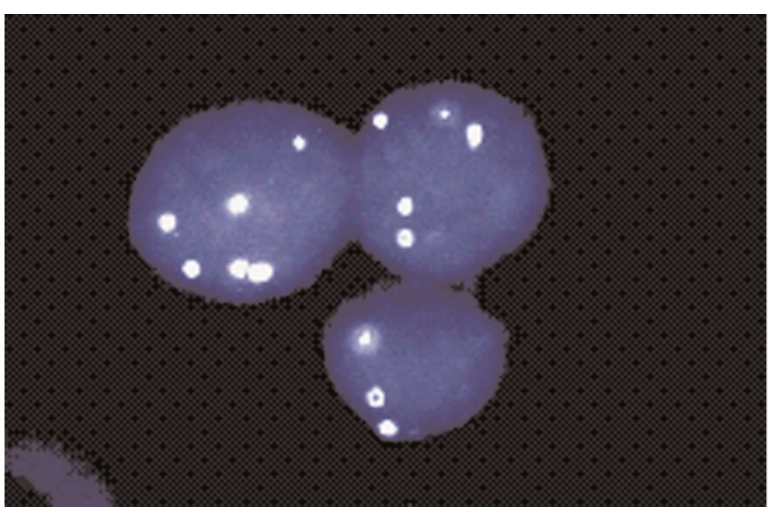

Fluorescence in situ hybridization (FISH) analysis of a ductal lavage specimen collected from a patient with invasive breast cancer and classified as cytologically benign reveals a rare cluster of cells exhibiting chromosomal aneusomy [39].

unmethylated copies [50]. Applied to breast fluids collected presurgically from breast cancer patients, these assays have successfully identified cancer-associated methylation events in a series of samples classified as negative for malignant cytology or as insufficiently cellular for cytological evaluation [51]. PCR-based loss of heterozygosity analysis has also been used to detect allelic losses at the BRCA1 gene in DNA isolated from the acellular fraction of lavage fluids collected from BRCA1 mutation carriers [52]. Although no malignant cytology was identified in the cellular fraction of these lavages, one of the carriers was subsequently diagnosed with an invasive breast tumor harboring a loss of heterozygosity alteration matching that of the lavage sample. $\mathrm{FISH}$ is also being applied to extend the analysis of cytology slides with the aim of stratifying the diagnostic and prognostic significance of cytological atypia [53].

While breast fluids may contain diluted quantities of malignant cells and genetic alterations, they harbor concentrated mixtures of proteins reflecting the epithelial, stromal, and infiltrating cell populations of the breast microenvironment. Two-dimensional gel analyses of nipple aspirate fluids have revealed the presence of over 1,000 distinct proteins and studies have reported average total protein concentrations in the $\mathrm{mg} / \mathrm{ml}$ range [54-56]. Altered levels of numerous cancer-associated protein markers, including carcinoembryonic antigen (CEA), prostate specific antigen (PSA), basic fibroblast growth factor (bFGF), urinary plasminogen activator (UPA), and human epidermal growth factor receptor-type 2 (HER-2/neu) have been detected in nipple aspirate fluids collected from breast cancer patients relative to healthy control women [42,57-62].

As no single protein is entirely tumor-specific or deregulated in all tumors, however, there is often significant overlap in the range of levels present in fluids from diseased versus healthy subjects. As such, the measurement of any single marker is sub-optimal and comprehensive approaches are better suited for interrogating complex breast fluids. To date, several groups have used SELDI-TOF MS (surface-enhanced laser desorption and ionization-time of flight mass spectrometry) to detect breast fluid protein profiles that are unique to breast cancer patients relative to healthy control women [54,63-69]. The identities of the differentially expressed proteins in these studies are currently being pursued with the goal of developing targeted and specific panels of protein markers useful for detection and risk assessment.

A recent multi-institutional study to develop comprehensive proteomic approaches for breast fluid analysis has identified human neutrophil peptides 1 to 3 as candidate biomarkers [64]. Interestingly, two of the studies that detected different profiles in breast cancer patients versus healthy women reported a conservation of proteomic signatures within the fluids collected from the cancer-bearing and healthy contralateral breast of the same patient $[65,66]$. The biological and/or technical explanations underlying these intriguing findings are not clear and the technical nuances of applying proteomic approaches to complex clinical samples are still evolving. However, because SELDI-TOF is highthroughput and can be applied to measure the complex protein mixtures present within the small microliter volumes easily collected by nipple aspiration, the development of this application holds enormous promise.

The ability of biomarkers to detect rare cells and soluble molecules provides significant advantages that are reflected in direct comparisons with exfoliative cytology. One strategy to evaluate intraductal approaches for the detection of abnormalities associated with breast cancer progression has been the paired study format, in which breast fluids are collected presurgically by nipple aspiration, lavage, or endoscopy from women scheduled for excisional breast biopsies or mastectomies. The paired sets of tissues and fluids have been evaluated by surgical pathological, cytological and biomarker analysis to define the sensitivity and specificity of detecting benign and malignant lesions. Although not formally validated, preliminary comparisons have consistently demonstrated superior sensitivities and specificities for biomarkers relative to cytology (Table 3). The highest sensitivities were achieved when biomarker analysis was applied to fluids from lesion-containing ducts confirmed by endoscopy in a comparison of cytology and FISH to evaluate lavage specimens for the diagnostic work-up of spontaneous nipple discharge [70]. This study reported low sensitivity for cytology, but $100 \%$ sensitivity and $100 \%$ specificity for FISH analysis. The comparatively higher sensitivity of markers in paired studies suggests that even if abnormal cells are not being shed into, or collected from, diseased ducts in adequate numbers for systematic detection by cytology, a variety of biomarkers appear to exhibit the 
required sensitivities to detect rare events signaling evidence of malignant progression.

\section{Conclusion}

At present we do not know the relative extent to which breast fluid properties reflect developmentally determined 'field effects', systemically controlled breast properties, and/or changes arising within individual ductal units. An important goal is to define this through a comprehensive analysis of interductal variation at the cellular, biochemical, genetic and proteomic levels in the normal and diseased breast. This will aid in determining the appropriate anatomic unit that should be sampled for predicting short- and long-term breast cancer risk. The value of these approaches will require evaluation through long-term follow-up studies, such as the multicenter SEDE (Serial Evaluation of Ductal Epithelium) trial currently being conducted by Cytyc, Inc., in which high-risk women are undergoing serial lavage at six-month intervals. This trial was initiated in 2004 and initial data are expected in 2007 [71].

Despite all the aforementioned gaps in our knowledge regarding the anatomy and physiology of the ductal systems, the above studies illustrate the power of biomarkers to detect abnormalities in breast fluids and to gauge the microenvironment of the breast, and suggest the potential to distill biological risk profiles for predicting short- and long-term breast cancer development. Importantly, 70\% of all breast cancer patients do not exhibit any of the risk factors incorporated by quantitative historical risk assessment tools such as the Gail and Claus models [72]. As such, direct analysis of the breast tissue with non-invasive techniques can extend risk assessment to the majority of women who are biologically predisposed to develop breast cancer. For example, the application of proteomic analyses to breast fluids may lead to the identification of global profiles reflecting field effects and/or systemic changes associated with predisposing systemic variables.

Several SELDI-TOF studies have detected different breast fluid profiles for breast cancer patients versus healthy control subjects. That these changes reflect global patterns associated with predisposition or early breast cancer progression is suggested by the fact that the differences are not detected between the diseased and healthy breasts of cancer patients. Detection of these early patterns would not rely on targeted sampling, as all ducts would be expected to harbor the changes. Proteomic analysis of easily obtainable NAF samples could potentially be used as a screening tool to identify women with elevated long-term risk. These women would then become candidates for heightened surveillance and/or more extensive ductal explorations with lavage and biomarker analysis to identify and track progression within specific ductal systems and even intraductal therapy.

The intraductal approach to the breast offers the opportunity to study the biology and tumorigenesis of the human breast from a new perspective. Although the clinical and scientific applications of the approach are currently hindered by basic gaps in our understanding of the anatomy and physiology of the ductal lobular systems, they have significant potential.

\section{Competing interests}

BLK declares that she has no competing interests. SML has acted as a consultant to Cytyc Health Corporation who manufacture the ductal lavage catheter and is the founder of a private company to commercialize intrductal therapy.

\section{References}

1. Jensen HM, Rice JR, Wellings SR: Preneoplastic lesions in the human breast. Science 1976, 191:295-297.

2. Ohtake T, Kimijima I, Fukushima T, Yasuda M, Sekikawa K, Takenoshita S, Abe R: Computer-assisted complete threedimensional reconstruction of the mammary ductal/lobular systems: implications of ductal anastomoses for breast-conserving surgery. Cancer 2001, 91:2263-2272.

3. Johnson-Maddux A, Ashfaq R, Cler L, Naftalis E, Leitch AM, Hoover S, Euhus DM: Reproducibility of cytologic atypia in repeat nipple duct lavage. Cancer 2005, 103:1129-1136.

4. Tot T: DCIS, cytokeratins, and the theory of the sick lobe. Virchows Arch 2005, 447:1-8.

5. Mai KT, Yazdi HM, Burns BF, Perkins DG: Pattern of distribution of intraductal and infiltrating ductal carcinoma: a three-dimensional study using serial coronal giant sections of the breast. Hum Pathol 2000, 31:464-474.

6. Holland R, Veling SH, Mravunac M, Hendriks JH: Histologic multifocality of Tis, T1-2 breast carcinomas. Implications for clinical trials of breast-conserving surgery. Cancer 1985, 56: 979-990.

7. King BL, Love SM, Rochman S, Kim JA: The Fourth International Symposium on the Intraductal Approach to Breast Cancer, Santa Barbara, California, 10-13 March 2005. Breast Cancer Res 2005, 7:198-204.

8. Cooper A: The Anatomy and Diseases of the Breast. Philadelphia: Lea and Blanchard; 1845

9. Love SM, Barsky SH: Anatomy of the nipple and breast ducts revisited. Cancer 2004, 101:1947-1957.

10. Teboul M, Halliwell M: Atlas of Ultrasound and Ductal Echography of the Breast: The Introduction of Anatomic Intelligence into Breast Imaging. Oxford, United Kingdom: Blackwell Science; 1995.

11. Ramsay DT, Kent JC, Hartmann RA, Hartmann PE: Anatomy of the lactating human breast redefined with ultrasound imaging. J Anat 2005, 206:525-534.

12. Sartorius OW, Smith HS, Morris P, Benedict D, Friesen L: Cytologic evaluation of breast fluid in the detection of breast disease. J Natl Cancer Inst 1977, 59:1073-1080.

13. Dietz JR, Crowe JP, Grundfest S, Arrigain S, Kim JA: Directed duct excision by using mammary ductoscopy in patients with pathologic nipple discharge. Surgery 2002, 132:582-587; discussion 587-588.

14. Going JJ, Moffat DF: Escaping from Flatland: clinical and biological aspects of human mammary duct anatomy in three dimensions. J Pathol 2004, 203:538-544.

15. Papanicolaou GN, Bader GM, Holmquist DG, Falk EA: Cytologic evaluation of breast secretions. Ann NY Acad Sci 1956, 63: 1409-1421.

16. Petrakis NL: Physiologic, biochemical, and cytologic aspects of nipple aspirate fluid. Breast Cancer Res Treat 1986, 8:7-19.

17. Wynder EL, Lahti H, Laakso K, Cheng SL, DeBevoise S, Rose DP: Nipple aspirates of breast fluid and the epidemiology of breast disease. Cancer 1985, 56:1473-1478.

18. Petrakis NL: Nipple aspirate fluid in epidemiologic studies of breast disease. Epidemiol Rev 1993, 15:188-195.

19. Chatterton RT Jr, Geiger AS, Mateo ET, Helenowski IB, Gann PH: Comparison of hormone levels in nipple aspirate fluid of preand postmenopausal women: effect of oral contraceptives and hormone replacement. J Clin Endocrinol Metab 2005, 90: 1686-1691. 
20. Chatterton RT Jr, Geiger AS, Gann PH, Khan SA: Formation of estrone and estradiol from estrone sulfate by normal breast parenchymal tissue. J Steroid Biochem Mol Biol 2003, 86:159166.

21. Chatterton RT Jr, Geiger AS, Khan SA, Helenowski IB, Jovanovic $\mathrm{BD}$, Gann $\mathrm{PH}$ : Variation in estradiol, estradiol precursors, and estrogen-related products in nipple aspirate fluid from normal premenopausal women. Cancer Epidemiol Biomarkers Prev 2004, 13:928-935.

22. Petrakis NL, Wrensch MR, Ernster VL, Miike R, Murai J, Simberg $\mathrm{N}$, Siiteri PK: Influence of pregnancy and lactation on serum and breast fluid estrogen levels: implications for breast cancer risk. Int J Cancer 1987, 40:587-591.

23. Leborgne RA: The Breast in Roentgen Diagnosis. Montevideo, Uruguay: Impresora Uruguaya SA - Juncal 1511; 1953.

24. Brogi E, Robson M, Panageas KS, Casadio C, Ljung BM, Montgomery L: Ductal lavage in patients undergoing mastectomy for mammary carcinoma: a correlative study. Cancer 2003, 98: 2170-2176.

25. Khan SA, Wiley EL, Rodriguez N, Baird C, Ramakrishnan R, Nayar R, Bryk M, Bethke KB, Staradub VL, Wolfman J, et al:: Ductal lavage findings in women with known breast cancer undergoing mastectomy. J Natl Cancer Inst 2004, 96:1510-1517.

26. Love SM, Barsky SH: Breast-duct endoscopy to study stages of cancerous breast disease. Lancet 1996, 348:997-999.

27. Sauter ER, Ehya H, Schlatter L, MacGibbon B: Ductoscopic cytology to detect breast cancer. Cancer J 2004, 10:33-41; discussion 15-36.

28. Dooley WC, Spiegel A, Cox C, Henderson R, Richardson L, Zabora J: Ductoscopy: defining its role in the management of breast cancer. Breast J 2004, 10:271-272.

29. Phillips HA, Howard GC, Miller WR: Nipple aspirate fluid in relation to breast cancer. Breast 1999, 8:169-174.

30. Higgins S, Matloff E, Rimm D, Dziura J, Haffty B, King B: Patterns of reduced nipple aspirate fluid production and ductal lavage cellularity in women at high risk for breast cancer. Breast Cancer Research 2005, 7:R1017-R1022.

31. Mitchell G, Antill Y, Murray W, Kirk J, Salisbury E, Lindeman G, Di lulio J, Milner A, Devereaux L, Phillips K-A: Nipple aspiration and ductal lavage in women with a germline BRCA1 or BRCA2 mutation. Breast Cancer Research 2005, 7:R1122-R1131.

32. Sanchez LM, Vizoso F, Diez-Itza I, Lopez-Otin C: Identification of the major protein components in breast secretions from women with benign and malignant breast diseases. Cancer Res 1992, 52:95-100.

33. Dooley WC, Ljung BM, Veronesi U, Cazzaniga M, Elledge RM, O'Shaughnessy JA, Kuerer HM, Hung DT, Khan SA, Phillips RF, et al.: Ductal lavage for detection of cellular atypia in women at high risk for breast cancer. J Natl Cancer Inst 2001, 93:16241632.

34. Kurian AW, Mills MA, Jaffee M, Sigal BM, Chun NM, Kingham KE, Collins LC, Nowels KW, Plevritis SK, Garber JE, et al:: Ductal lavage of fluid-yielding and non-fluid-yielding ducts in BRCA1 and BRCA2 mutation carriers and other women at high inherited breast cancer risk. Cancer Epidemiol Biomarkers Prev 2005, 14:1082-1089.

35. Bhandare D, Nayar R, Bryk M, Hou N, Cohn R, Golewale N, Parker NP, Chatterton RT, Rademaker A, Khan SA: Endocrine biomarkers in ductal lavage samples from women at high risk for breast cancer. Cancer Epidemiol Biomarkers Prev 2005, 14: 2620-2627.

36. Maddux AJ, Ashfaq R, Naftalis E, Leitch AM, Hoover S, Euhus D: Patient and duct selection for nipple duct lavage. Am J Surg 2004, 188:390-394.

37. Khan SA, Wolfman JA, Segal L, Benjamin S, Nayar R, Wiley EL, Bryk $M$, Morrow $M$ : Ductal lavage findings in women with mammographic microcalcifications undergoing biopsy. Ann Surg Oncol 2005, 12:689-696.

38. King EB, Chew KL, Petrakis NL, Ernster VL: Nipple aspirate cytology for the study of breast cancer precursors. J Natl Cancer Inst 1983, 71:1115-1121.

39. King BL, Tsai SC, Gryga ME, D'Aquila TG, Seelig SA, Morrison LE, Jacobson KK, Legator MS, Ward DC, Rimm DL, et al.: Detection of chromosomal instability in paired breast surgery and ductal lavage specimens by interphase fluorescence in situ hybridization. Clin Cancer Res 2003, 9:1509-1516.

40. Krishnamurthy S, Sneige N, Thompson PA, Marcy SM, Singletary
SE, Cristofanilli M, Hunt KK, Kuerer HM: Nipple aspirate fluid cytology in breast carcinoma. Cancer 2003, 99:97-104.

41. Mendrinos S, Nolen JD, Styblo T, Carlson G, Pohl J, Lewis M Ritchie J: Cytologic findings and protein expression profiles associated with ductal carcinoma of the breast in ductal lavage specimens using surface-enhanced laser desorption and ionization-time of flight mass spectrometry. Cancer 2005, 105:178-183.

42. Inaji $\mathrm{H}$, Yayoi E, Maeura $\mathrm{Y}$, Matsuura $\mathrm{N}$, Tominaga $\mathrm{S}$, Koyama $\mathrm{H}$, Takatsuka $Y$, Mori T: Carcinoembryonic antigen estimation in nipple discharge as an adjunctive tool in the diagnosis of early breast cancer. Cancer 1987, 60:3008-3013.

43. Krassenstein R, Sauter E, Dulaimi E, Battagli C, Ehya H, KleinSzanto A Cairns P: Detection of breast cancer in nipple aspirate fluid by CpG island hypermethylation. Clin Cancer Res 2004, 10:28-32.

44. Dupont WD, Page DL: Risk factors for breast cancer in women with proliferative breast disease. N Engl J Med 1985, 312:146151.

45. Dupont WD, Parl FF, Hartmann WH, Brinton LA, Winfield AC, Worrell JA, Schuyler PA, Plummer WD: Breast cancer risk associated with proliferative breast disease and atypical hyperplasia. Cancer 1993, 71:1258-1265.

46. Wrensch MR, Petrakis NL, King EB, Miike R, Mason L, Chew KL, Lee MM, Ernster VL, Hilton JF, Schweitzer R, et al: Breast cancer incidence in women with abnormal cytology in nipple aspirates of breast fluid. Am J Epidemiol 1992, 135:130-141.

47. Wrensch MR, Petrakis NL, Miike R, King EB, Chew K, Neuhaus J, Lee MM, Rhys M: Breast cancer risk in women with abnormal cytology in nipple aspirates of breast fluid. J Nat/ Cancer Inst 2001, 93:1791-1798.

48. Fabian CJ, Kimler BF, Zalles CM, Klemp JR, Kamel S, Zeiger S, Mayo MS: Short-term breast cancer prediction by random periareolar fine-needle aspiration cytology and the Gail risk model. J Natl Cancer Inst 2000, 92:1217-1227.

49. Page DL, Dupont WD, Rogers LW, Rados MS: Atypical hyperplastic lesions of the female breast. A long-term follow-up study. Cancer 1985, 55:2698-2708.

50. Fackler MJ, McVeigh M, Mehrotra J, Blum MA, Lange J, Lapides A Garrett E, Argani P, Sukumar S: Quantitative multiplex methylation-specific PCR assay for the detection of promoter hypermethylation in multiple genes in breast cancer. Cancer Res 2004, 64:4442-4452.

51. Evron E, Dooley WC, Umbricht CB, Rosenthal D, Sacchi N Gabrielson E, Soito AB, Hung DT, Ljung B, Davidson NE, et al.: Detection of breast cancer cells in ductal lavage fluid by methylation-specific PCR. Lancet 2001, 357:1335-1336.

52. Isaacs $C$, Cavalli LR, Cohen $Y$, Pennanen M, Shankar LK, Freedman M, Singh B, Liu M, Gallagher A, Rone JD, et al:: Detection of $\mathrm{LOH}$ and mitochondrial DNA alterations in ductal lavage and nipple aspirate fluids from hngh-risk patients. Breast Cancer Res Treat 2004, 84:99-105.

53. Krishnamurthy S, Zhao L, Hayes K, Glassman AB, Cristofanilli M, Singletary SE, Hunt KK, Kuerer HM, Sneige N: Feasibility and utility of using chromosomal aneusomy to further define the cytologic categories in nipple aspirate fluid specimens: a preliminary study. Cancer 2004, 102:322-327.

54. Alexander H, Stegner AL, Wagner-Mann C, Du Bois GC, Alexander S, Sauter ER: Proteomic analysis to identify breast cancer biomarkers in nipple aspirate fluid. Clin Cancer Res 2004, 10: 7500-7510.

55. Kuerer HM, Goldknopf IL, Fritsche H, Krishnamurthy S, Sheta EA, Hunt KK: Identification of distinct protein expression patterns in bilateral matched pair breast ductal fluid specimens from women with unilateral invasive breast carcinoma. Highthroughput biomarker discovery. Cancer 2002, 95:2276-2282.

56. Varnum SM, Covington CC, Woodbury RL, Petritis K, Kangas LJ, Abdullah MS, Pounds JG, Smith RD, Zangar RC: Proteomic characterization of nipple aspirate fluid: identification of potential biomarkers of breast cancer. Breast Cancer Res Treat 2003, 80:87-97.

57. Foretova L, Garber JE, Sadowsky NL, Verselis SJ, Joseph DM, Andrade AF, Gudrais PG, Fairclough D, Li FP: Carcinoembryonic antigen in breast nipple aspirate fluid. Cancer Epidemiol Biomarkers Prev 1998, 7:195-198.

58. Kuerer HM, Thompson PA, Krishnamurthy S, Fritsche HA, Marcy SM, Babiera GV, Singletary SE, Cristofanilli M, Sneige N, Hunt 
KK: High and differential expression of HER-2/neu extracellular domain in bilateral ductal fluids from women with unilateral invasive breast cancer. Clin Cancer Res 2003, 9:601-605.

59. Liu $Y$, Wang JL, Chang H, Barsky SH, Nguyen M: Breast-cancer diagnosis with nipple fluid bFGF. Lancet 2000, 356:567.

60. Qin W, Zhu W, Wagner-Mann C, Folk W, Sauter ER: Association of UPA, PAT-1, and UPAR in nipple aspirate fluid (NAF) with breast cancer. Cancer J 2003, 9:293-301.

61. Sauter ER, Daly M, Linahan K, Ehya H, Engstrom PF, Bonney G, Ross EA, Yu H, Diamandis E: Prostate-specific antigen levels in nipple aspirate fluid correlate with breast cancer risk. Cancer Epidemiol Biomarkers Prev 1996, 5:967-970.

62. Zhao Y, Verselis SJ, Klar N, Sadowsky NL, Kaelin CM, Smith B, Foretova L, Li FP: Nipple fluid carcinoembryonic antigen and prostate-specific antigen in cancer-bearing and tumor-free breasts. J Clin Oncol 2001, 19:1462-1467.

63. Kuerer HM, Coombes KR, Chen JN, Xiao L, Clarke C, Fritsche H, Krishnamurthy S, Marcy S, Hung MC, Hunt KK: Association between ductal fluid proteomic expression profiles and the presence of lymph node metastases in women with breast cancer. Surgery 2004, 136:1061-1069.

64. Li J, Zhao J, Yu X, Lange J, Kuerer H, Krishnamurthy S, Schilling $\mathrm{E}$ Khan SA, Sukumar S, Chan DW: Identification of biomarkers for breast cancer in nipple aspiration and ductal lavage fluid. Clin Cancer Res 2005, 11:8312-8320.

65. Paweletz CP, Trock B, Pennanen M, Tsangaris T, Magnant C, Liotta LA, Petricoin EF: Proteomic profiles of nipple aspirate fluids obtained by SELDI-TOF: Potential for new biomarkers to aid in the diagnosis of breast cancer. Disease Markers 2001, 17:301-307.

66. Pawlik TM, Fritsche $\mathrm{H}$, Coombes KR, Xiao L, Krishnamurthy $\mathrm{S}$, Hunt KK, Pusztai L, Chen JN, Clarke CH, Arun B, et al:: Significant differences in nipple aspirate fluid protein expression between healthy women and those with breast cancer demonstrated by time-of-flight mass spectrometry. Breast Cancer Res Treat 2005, 89:149-157.

67. Petricoin EE, Paweletz CP, Liotta LA: Clinical applications of proteomics: proteomic pattern diagnostics. J Mammary Gland Biol Neoplasia 2002, 7:433-440.

68. Sauter ER, Shan S, Hewett JE, Speckman P, Du Bois GC: Proteomic analysis of nipple aspirate fluid using SELDI-TOF-MS. Int J Cancer 2005, 114:791-796.

69. Sauter ER, Zhu W, Fan XJ, Wassell RP, Chervoneva I, Du Bois GC: Proteomic analysis of nipple aspirate fluid to detect biologic markers of breast cancer. Br J Cancer 2002, 86:14401443.

70. Yamamoto D, Senzaki $H$, Nakagawa $H$, Okugawa $H$ Gondo $H$, Tanaka K: Detection of chromosomal aneusomy by fluorescence in situ hybridization for patients with nipple discharge. Cancer 2003, 97:690-694.

71. Linder J: Editorial: ductal lavage of the breast. Diagn Cytopathol 2004, 30:140-142.

72. Hollingsworth $A B$, Nall $S$, Dill $D$ : The evolution of breast cancer risk assessment. J Okla State Med Assoc 2002, 95:639-644.

73. Miyazaki M, Tamaki Y, Sakita I, Fujiwara Y, Kadota M, Masuda N, Ooka M, Ohnishi T, Ohue M, Sekimoto M, et al.: Detection of microsatellite alterations in nipple discharge accompanied by breast cancer. Breast Cancer Res Treat 2000, 60:35-41. 